\title{
PREVALENCE AND HISTOPATHOLOGICAL CHANGES OF BOVINE FASCIOLIASIS, WITH UNUSUAL MIGRATION TO LUNG IN NEW-VALLEY GOVERNORATE
}

\author{
SOTOHY A. SOTOHY ${ }^{1}$; ABDALLAH A. HASSAN ${ }^{2}$; WAFAA G. MAHMOUD ${ }^{3}$ and \\ ABEER A. KHEDR ${ }^{3}$ \\ ${ }^{1}$ Department of Animal and Environmental Hygiene, Fac. of Vet. Medicine, Assiut University \\ ${ }^{2}$ Department of Parasitology, Faculty of Medicine, Assiut University \\ ${ }^{3}$ Department of Parasitology, Faculty of Veterinary, Medicine, New-Valley University
}

Received: 17 March 2019; Accepted: 27 March 2019

\begin{abstract}
The main objectives of this study were to determine the prevalence of fascioliasis in cattle, and to describe the histopathological changes in liver and lung. A total of 600 slaughtered bull's $1 \leq 2$ years were examined grossly to investigate Fasciola infection, from abattoirs in New-Valley Governorate. The livers of 120 bulls (20\%) were positive for fascioliasis, with unusual migration to lung. The results indicated that Fasciola hepatica was more prevalent than other flukes infections including Fasciola gigantica and Fasciola hepatogigantica (58.3 vs. 12.5 and $29.2 \%$, respictivelly). The histopathological examinations illustrate the presence of acute fascioliasis $(66.7 \%)$, chronic fascioliasis $(33.3 \%)$, and ectopic lesion of Fascioliasis (3.3\%). From the above results it could be concluded that bovine fascioliasis is endemic in New -Valley, constitutes a major cause of economic losses and threat public health.
\end{abstract}

Key words: Fasciola infection, bulls, histopathological changes, ectopic lesion, New-Valley Governorate.

\section{INTRODUCTION}

Fascioliasis is a serious infectious parasitic disease infecting domestic ruminants and humans, worldwide. The mortality due to animal fascioliasis in Egypt, were estimated by about 190 million animals per year according to the Egyptian Academy of Scientific Research and Technology Report (Kuraa and Malek, 2014). Fascioliasis is responsible for immense economic losses in cattle in terms of condemnation of livers, reduces animal reproductively, weight gain, and the production of meat and milk (Elshraway and Mahmoud, 2017). Ruminant fascioliasis infection occurs after ingestion of forage containing metacercarial cyst, which excyst in the gut, and penetrate the intestinal wall migrate through the peritoneal cavity and enter the bile duct and liver parenchyma. Occasionally, some flukes wander in the peritoneal cavity and other ectopic areas, producing lesions in the eye, brain, lungs, skin and other ectopic foci of host tissues (Nappi, 2002). Meat inspection provides vital data and valuable information on the incidences and prevalence of animal diseases and conditions within

Corresponding author: Dr. ABEER A. KHEDR E-mail address: Abeer.lalhmd49@gmail.com

Present address: Department of Parasitology, Faculty of Veterinary, Medicine, New-Valley University any country to prevent the transmission of infectious and zoonotic diseases to humans. Documentation and collection of this information will make changes in animal husbandry practices and disease control (Phiri, 2006). This study is conducted to determine the prevalence of fascioliasis infections in cattle by studying the gross and microscopic morphological features of the parasitic stages, and describe the histopathological changes in liver and lung.

\section{MATERIALS AND METHODS}

The study was conducted in the El-Kharga abattoirs in New Valley Governorate.

\section{Samples collection}

A total of 600 slaughtered bull at age $\leq 2$ years, were daily inspected for the presence of liver fascioliasis from May 2017 to November 2018, which efficiently inspected by naked eye and palpation for the presence of gross lesion and the worms then further examinations.

\section{Post mortem examination:}

The livers and lungs inspected by making multiple cuts to check the presence of fascioliasis, palpated, and photographed for any Fasciola, all retained worms of Fasciola sp. were stained with acetic acid - alum carmine (Garcia and Bruckner, 2001), Then 
identified by the morphological features of the agent (Arjmand et al., 2015).

\section{Histopathological examination:}

Specimens from affected livers were immediately taken and immersed in $10 \%$ formalin. After proper fixation, the specimens were trimmed, washed, dehydrated in ascending grades of ethyl alcohol, then cleared in xylene and embedded in paraffin .Thin sections about 4-6 microns in thickness were prepared and stained with haematoxylin and eosin stain for general microscopic examination according to (Bancroft and Cook, 1994). The prepared permanent slides were mounted and examined on light microscope and viewed at different magnifications.

\section{RESULTS}

From 600 slaughtered bull at age $\leq 2$ years, the prevalence rate of the total Fasciola infection was 20\%. Results in Fig.1, showed that the bovine fascioliasis was higher during autumn and spring than summer and winter ( 31 and $21.1 \%$ vs. 18.5 and $13.9 \%)$, respectively.

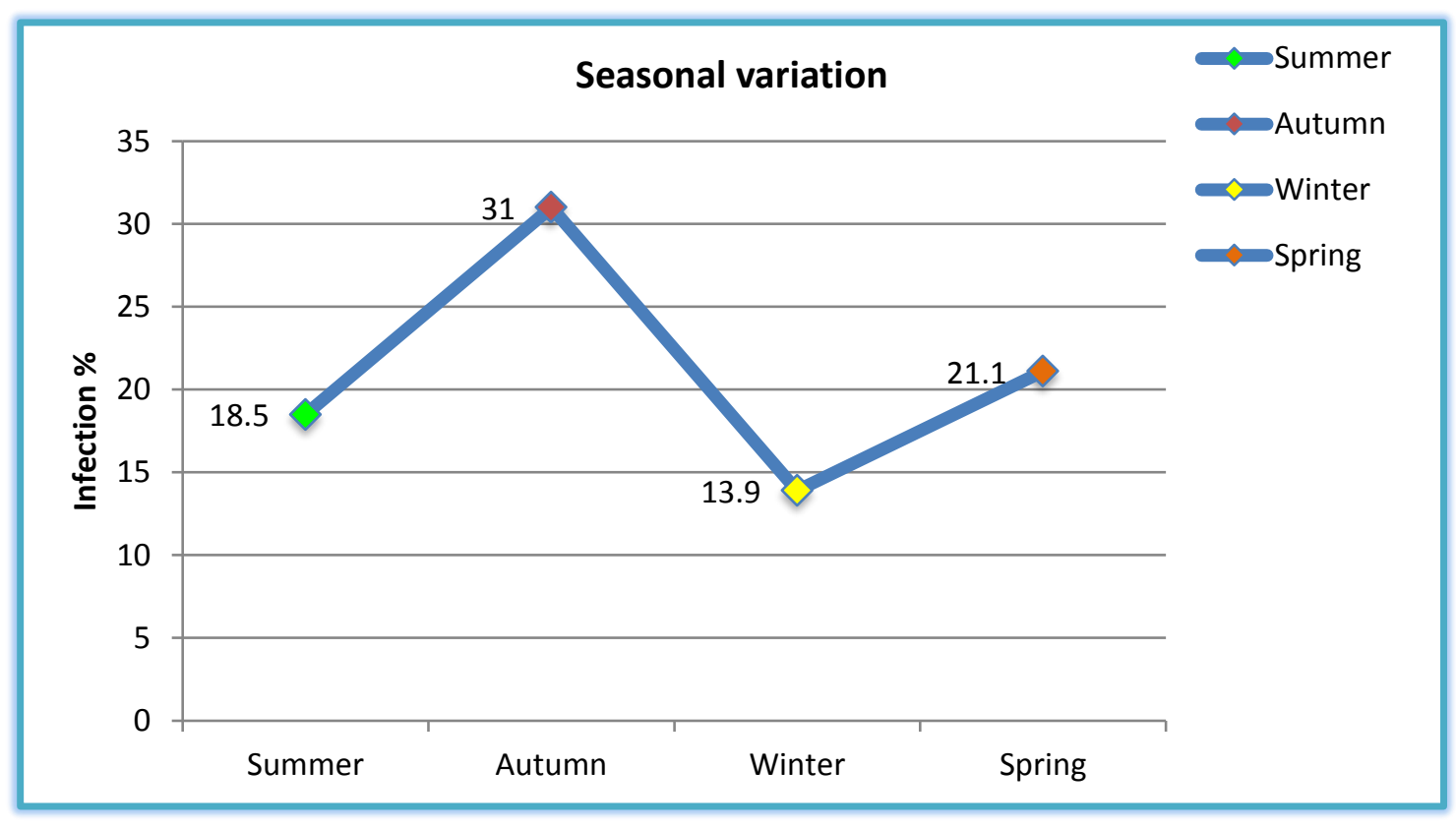

Fig. 1: Seasonal variation of fascioliasis in slaughtered cattle at El-kharga abattoir.

\section{Post mortem examination}

The results of examined 120 Fasciola infected livers on the current study (Table 1), refer that, $F$. hepatica was the most commonly parasite with higher prevalence rate $(58.3 \%)$. However, the prevalence rate of $F$. hepatogigantica and $F$. gigantica was (29.2 and 12.5\%), respectively. Macroscopic examination of retained Fasciola from tissue appeared grayish brown leaf- like. The measurements of $F$. hepatica was $2-3 \mathrm{~cm}$ in length and about $0.5-1.5 \mathrm{~cm}$ in breadth. The microscopic features of $F$. hepatica were the oral sucker at the conical anterior end equal in size with ventral sucker which located in at the level of the shoulder. The inner intestinal branches are rudimentary. Testes were highly branched, tandem in position and located at the middle third of the body. Macroscopic examination of $F$. gigantica was measured about 3-8 $\mathrm{cm}$ in length and about $0.5-1.5 \mathrm{~cm}$ in breadth, microscopically; the oral sucker was at the anterior end and ventral sucker was larger. The intestinal caeca were branched and characterized by $\mathrm{T}$ and $\mathrm{Y}$ shaped branches. Testes were highly branched, tandem in position and located at the middle third of the body. In case of $F$. hepatogigantica, it is an intermediate form having few morphological characters from Fasciola hepatica and Fasciola gigantica (Fig.2) which is genetically confirmed by (Khalifa et al., 2013). 


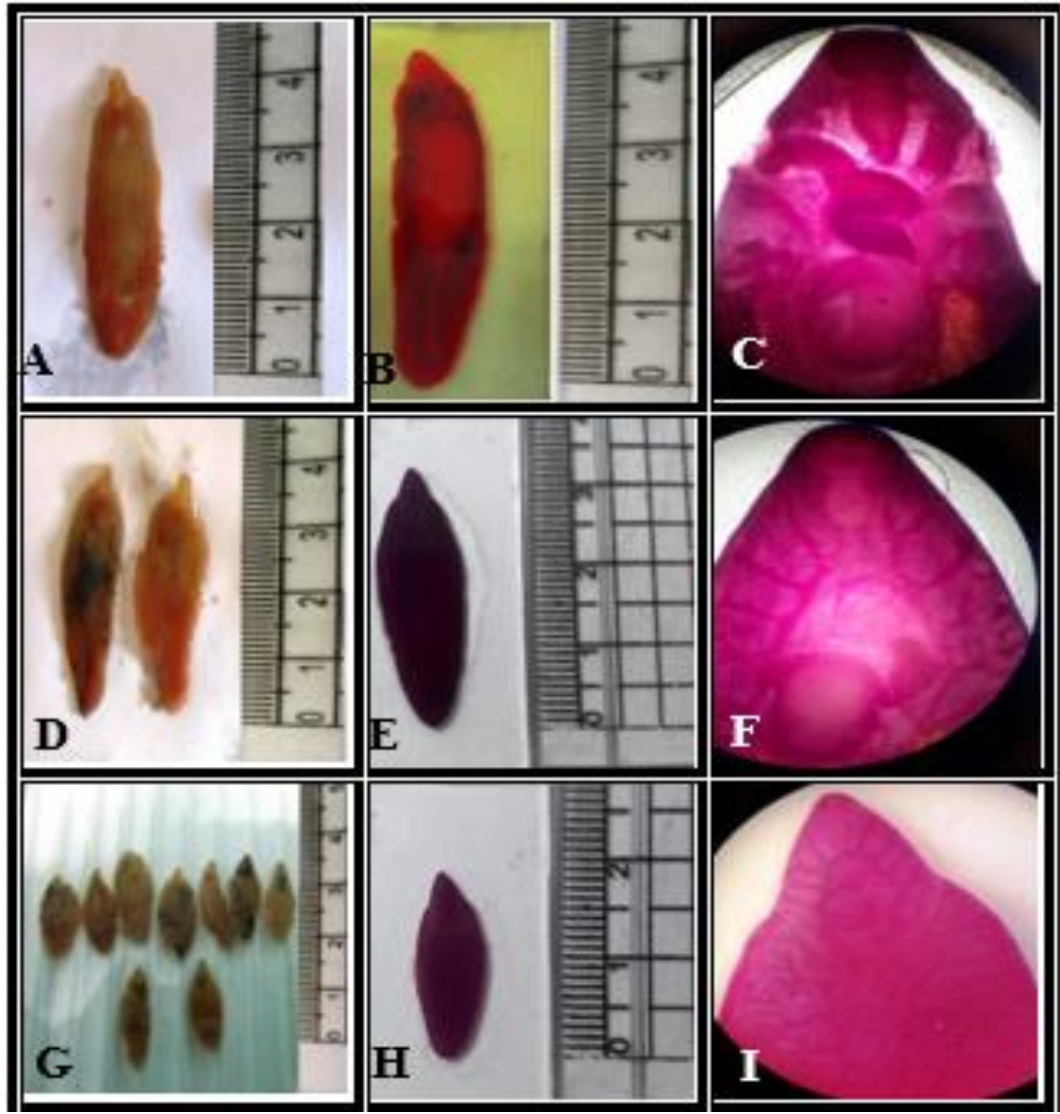

Fig. 2: Unstained

Fasciola hepatica (G), Fasciola hepatogigantica (D) and Fasciola gigantica (A)

- Stained with alum carmine

Fasciola hepatica (H), Fasciola hepatogigantica (E) and Fasciola gigantica (B)

- Anterior end of

Fasciola hepatica (I), Fasciola hepatogigantica (F) and Fasciola gigantica (C)

Table 1: Species of Fasciola encountered in infected livers.

\begin{tabular}{lcc}
\hline Species of Fasciola & NO. & \% \\
\hline F. hepatica & 70 & 58.3 \\
F. hepatogigantica & 35 & 29.2 \\
F. gigantica & 15 & 12.5 \\
Total & 120 & 100.00 \\
\hline
\end{tabular}

normal sized liver showed areas of cirrhosis and thickened calcified bile duct wall (Fig.4). The ectopic lesion was found in $3.3 \%$ of animal's lung that suffered from chronic fascioliasis. The ectopic lesions in lung were detected when the affected liver contains huge number of Fasciola. The gross appearance of lung showed that the pulmonary parenchyma was firm in consistency and a few number of immature flukes were encapsulated in cysts (Fig.7A and 7B).
As illustrated in (Table 2) the percentage of acute fascioliasis was $66.7 \%$. The gross pathological changes of the liver were enlarged, firm, congested and oozing blood freely from the cut surface (Fig.3). The percentage of chronic fascioliasis was $33.3 \%$. Grossly the livers were mostly small in size and firm in consistency with corrugated capsule. Mature liver flukes were occasionally observed within the lumen of the thickened bile ducts. Black minute granules (hematoporphyrin pigment) of gritty sensation were found in the bile duct. On the other hand, some

Table 2: The results for the histopathological examination.

\begin{tabular}{lcc}
\hline Pathological lesion & NO. & \% \\
\hline Acute fascioliasis & 80 & 66.7 \\
Chronic fascioliasis & 40 & 33.3 \\
\hline
\end{tabular}




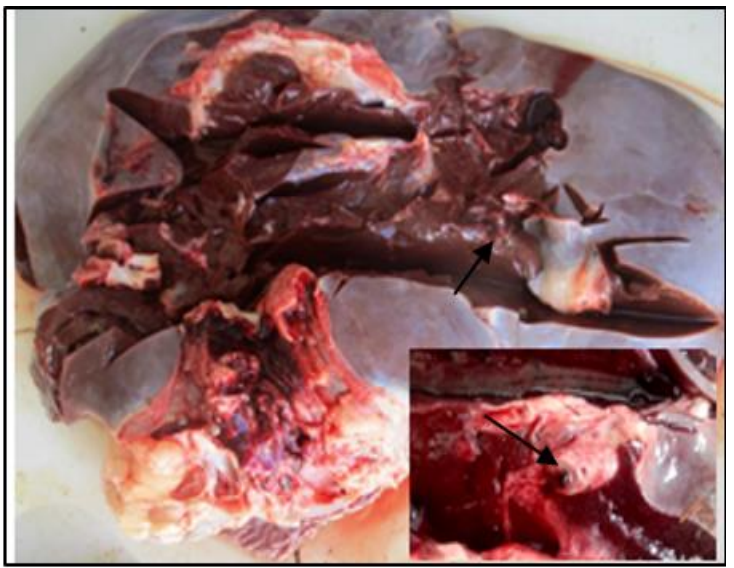

Fig. 3: Macroscopic liver fascioliasis showing enlarged and firm liver with Fasciola sp. in bile duct.

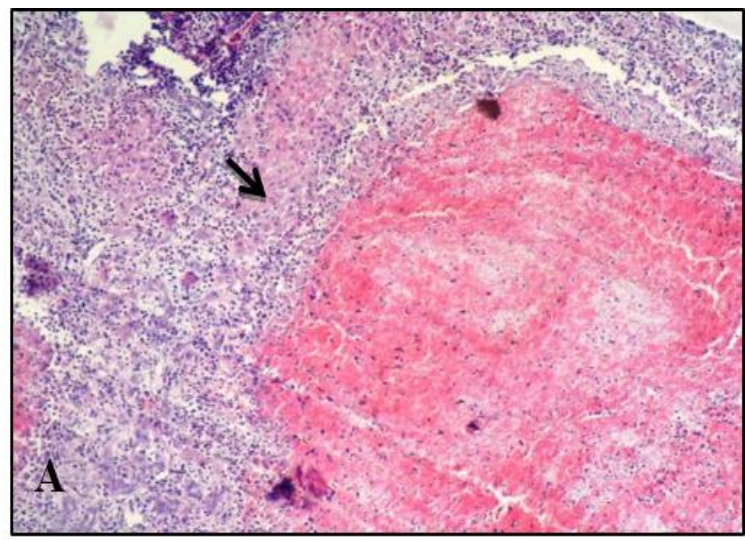

Fig. 5 A: Liver showing migratory tract of fasciola containing necrosis \& haemorrhage (H \& E x4).

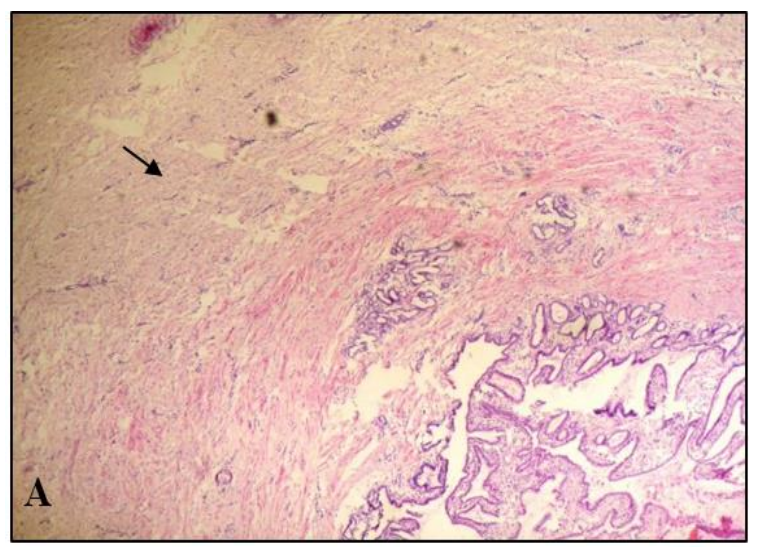

Fig. 6 A: Chronic cholangitis and bile duct hyperplasia H \& E (x10).

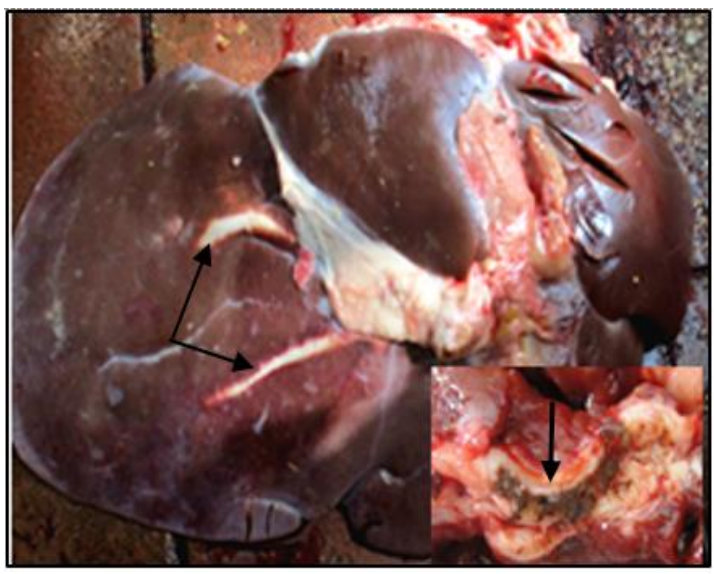

Fig. 4: Macroscopic liver fascioliasis showing engorgement of bile duct hematoporphyrin pigment.

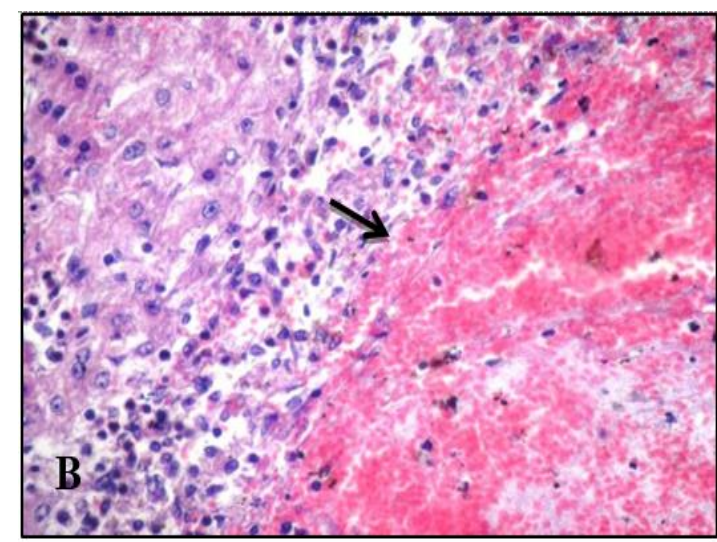

Fig. 5 B: Higher magnification of (Fig. A) H \& $\mathrm{E}(\mathrm{x} 10)$.

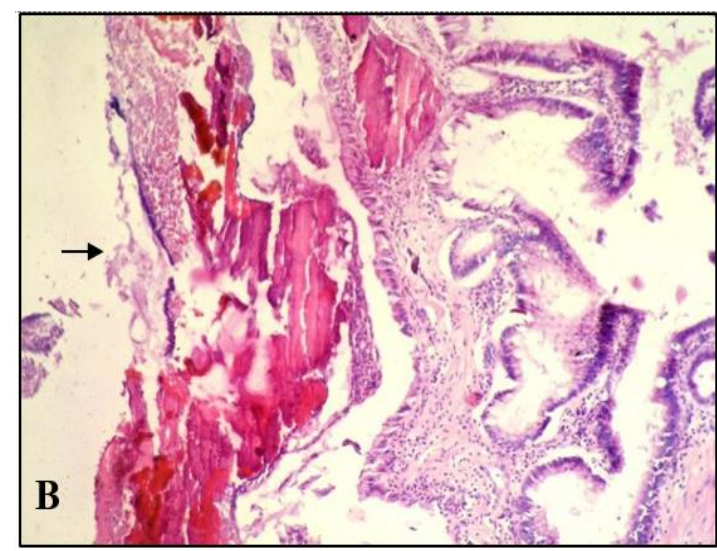

Fig. 6 B: Dead and calcified parasite $H$ \& E (x10). 


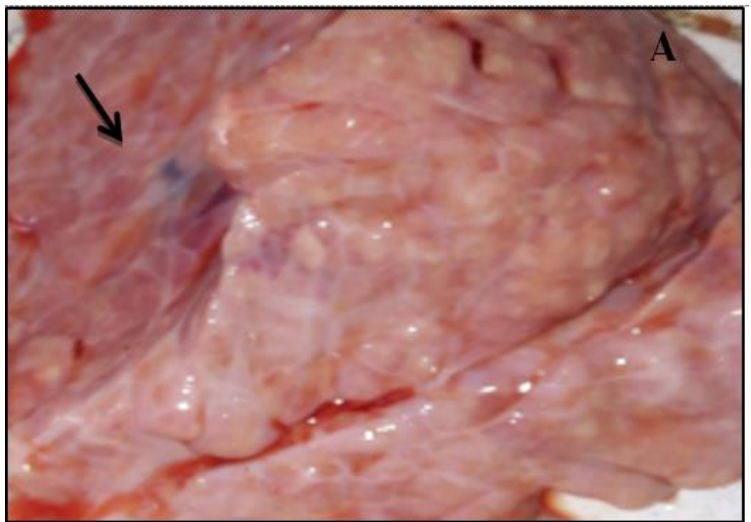

Fig. 7A: Lung showing encapsulated Fasciola sp.

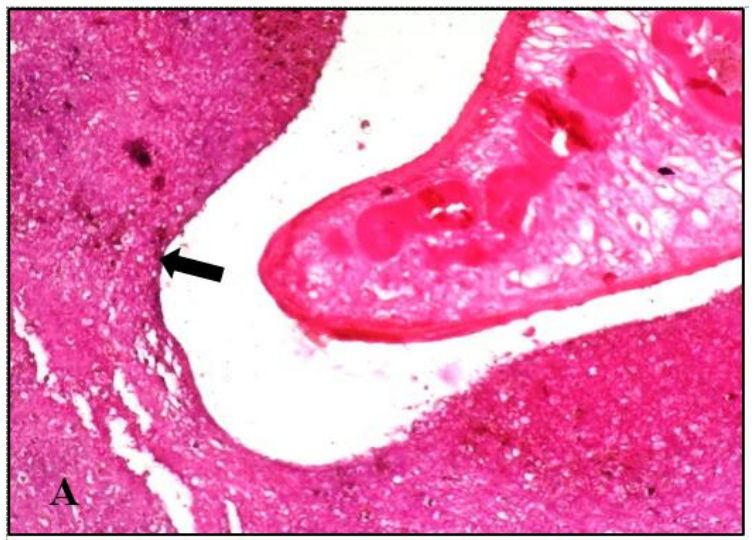

Fig. 8A: Lung showing immature fluke encapsulated by connective tissue H \& E (x10).

The histopathological examination of liver.

a) Acute fascioliasis revealed the presence of hemorrhagic migrating tracts formed from degenerated hepatocytes and erythrocytes (Fig.5A) \& (Fig.5B).

b) Chronic fascioliasis was characterized by chronic cholangitis and hyperplasia in bile duct (Fig.6A), and the presence of dead and calcified parasite (Fig.6B).

The histopathological examination of the lung. The immature flukes encapsulated by connective tissue (Fig.8A). and multiple area of necrosis with hemorrhage caused by young flukes which led to hemosiderosis were consistently observed (Fig.8B).

\section{DISCUSSION}

Fascioliasis is an important parasitic disease of domestic ruminants and occurs worldwide as a result of infection with liver fluke species (Hashemnia et al., 2015). The overall prevalence rate of fascioliasis in the examined bulls slaughtered in the El-Kharga abattoir was about $20 \%$ which nearly agreed with Njoku-Tony (2011) who found $23.3 \%$ of examined cattle, in Nigeria. On other hand, higher frequency of fascioliasis have been recorded by Kuchai et al. (2011) who reported $51.42 \%$, in Iran.

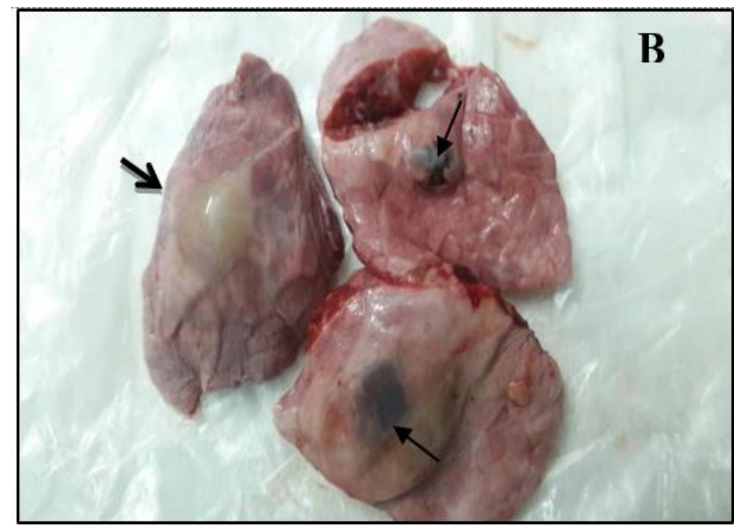

Fig. 7B: Lung showing cyst containing Fasciola sp.

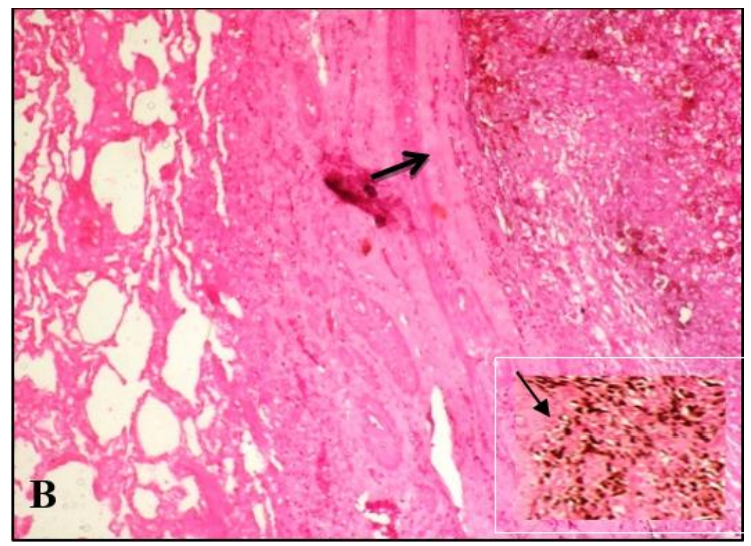

Fig. 8B: Lung showing hemosiderosis H \& E (x10).

Also, Iboyi et al. (2017) found that the prevalence was about $42 \%$ in Nigeria. Similar results was reported by Akoji et al. (2015) in cattle (41.7\%). However, there were some remarkable lower results detected in Egypt by Elmonir et al. (2015) 0.2\%, Borai et al. (2013) $2.67 \%$ and Youssef et al. (2013) $1.46 \%$. In the current study the highest infection rate was observed in autumn season $(31 \%)$ followed by spring and summer (21.1 and $18.5 \%)$, respectively. but the lowest rate observed in winter $13.9 \%$. The results in our study was agreement with Rahman et al. (2017) who found that the proportion of fascioliasis cases was the highest in from September to November $(28.7 \%)$ and the lowest rate in winter season (20.8\%). However, Elshraway and Mahmoud (2017) reported that the highest fascioliasis infection was found in winter $(35.04 \%)$. The distribution of $F$. hepatica depends upon many factors, such as ecoclimatic factors and regional differences in management practices (Mehmood et al., 2017). The prevalence rate of liver flukes in herbivores varies considerably throughout the world. The previous study by Dar et al. (2012) in Egypt observed that the prevalence rate of $F$. hepatica and $F$. gigantica in cattle $(69.4 \%)$ and $(30.6 \%)$, respectively. Post mortem examination on the 120 Fasciola infected livers of the current results indicated that $F$. hepatica and $F$. hepatogigantica were the main Fasciola 
species in the survey regions, however, F.hepatica were found to be the predominant Facsiola species causing bovine fascioliasis. Similar results was confirmed by Arjmand et al. (2015) at Ahvaz Abattoir, Iran, he found that the percentage of $F$. hepatica in the infected livers was $67.54 \%$.

The gross pathological lesions of acute fascioliasis among the affected livers reveal that the majority of livers were enlarged, firm, congested and oozing blood freely from the cut surface. These lesions were in complete agreement with those obtained by Borai et al. (2013), and in disagreement with Badr and Nasr (2009) who reported the presence of multiple soft abscesses on the liver surface and a viscous yellow material oozed from the cut ends, during the cut section. The abscesses were surrounded by hyperemic zone. The microscopically findings in the current study revealed that hemorrhagic migrating tracts formed from degenerated hepatocytes and erythrocytes. These lesions agree with those mentioned by Borai et al. (2013). On the other hand, Okoye et al. (2015) observed that the formation of granuloma around flukes formed from the eosinophil granulocytes, along with inflammatory molecules. In the current study the chronic fascioliasis, the livers were mostly small in size and firm in consistency with corrugated capsule. Mature liver flukes were occasionally observed within the lumen of the thickened bile ducts. Black minute granules (hematoporphyrin pigment) of gritty sensation were found in the bile duct. However, some normal sized liver showed areas of cirrhosis and thickened calcified bile duct wall. This result was similar with that reported by Borai et al. (2013) and Arjmand et al. (2015). Microscopically, Liver characterized by chronic cholangitis and hyperplasia in bile duct. Dead and calcified parasite can be seen. Which is similar to that mentioned by Okaiyeto et al. (2012). On other hand, Salmo et al. (2014) reported that invasion of the liver by migrating immature liver fluke damages the tissue and provide anaerobic condition, that allowed the germination and proliferation of bacteria that induce hepatocellular necrosis and abscess formation. However gross findings of lung revealed that the pulmonary parenchyma was firm in texture and a few numbers of immature flukes were encapsulated and can be seen randomly. Similar results, mentioned by Hashemnia et al. (2015). Similarly, the unusual migration to lung may be the result of aberrant migration of parasite to other organs specially lung (Eslami 2006). The results of histopathological studies agreement with Hashemnia et al. (2015) who indicated that the immature flukes encapsulated by connective tissue. Multiple areas of necrosis and hemorrhage caused by young flukes which led to hemosiderosis.

\section{CONCLUSIONS}

Slaughterhouse survey may be a good tool to monitor the status of infectious disease especially those of public health importance. The present study revealed a moderate fascioliasis infection in cattle, in El-Kharga, New Valley Governorate with unusual migration of Fasciola spp. into the lung and recommended that:- (awareness should be taken to increase the public health) Veterinary services are important to advice farmers to maintain their animals free from parasites by keeping the animals under hygienic conditions away from grazing in the infected pasture and provide them with safe drinking water source that is free from snails. Fascioliasis control at farm to diminish the economic losses due to infection.

\section{REFERENCES}

Akoji, O.; Akpabio, U. and Ngulukun, S. (2015): An Abattoir Study on the Prevalence of Fasciolosis in Cattle Slaughtered at Ubakala Slaughter House, Abia State, Nigeria. European Journal of Applied Sciences, 7(6): 250-254.

Arjmand, J.; Hajipour, N.; Khojasteh, S.M.B.; Baran, A.I.; Mirshekar, F.; Ghashghaei, O.; Samiei, K. and Faramarzpour, A. (2015): Prevalence, macroscopic and microscopic lesions of bovine fasciolosis at Ahvaz abattoir, Khozestan province, Iran. Biological Forum - An International Journal, 7(1): 539-545.

Badr, S.I. and Nasr, E.M. (2009): Histopathological and bacteriological studies on livers affected with fascioliasis in cattle. Egyptain Journal of Comparative Pathology Clinical Pathology, 22(1): 19-45.

Bancroft, J.D. and Cook, H.C. (1994): Manual of histological techniques and their diagnostic application Churchill Livingstone.

Borai, G.M.; Nagi, A.A.; Gab-Allah, S.M.; ElMashad, I.A. and Moustafa, A.S. (2013): Comparative pathological studies on parasitic affections of liver in farm animals (Doctoral dissertation, MSc. thesis).

Dar, Y.; Amer, S.; Mercier, A.; Courtioux, B. and Dreyfuss, G. (2012): Molecular identification of Fasciola spp. (digenea: Fasciolidae) in Egypt. Parasite: journal de la Société Française de Parasitologie, 19(2): 177-182.

Elmonir, W.; Mousa, W. and Sultan, K. (2015): The Prevalence of Some Parasitic Zoonoses in Different Slaughtered Animal Species at Abattoir in the Mid-Delta of Egypt; with Special Reference to its Economic Implications. Alexandria Journal for Veterinary Sciences, 47(1): 97-103. 
Elshraway, N.T. and Mahmoud, W.G. (2017): Prevalence of fascioliasis (liver flukes) infection in cattle and buffaloes slaughtered at the municipal abattoir of El-Kharga, Egypt. Veterinary world, 10(8): 914-917.

Eslami, A. (2006): Veterinary helminthology, vol. 1, Trematoda. Tehran University Publication, Tehran, pp 60-80

Garcia, L.S. and Bruckner, D.A. (2001): Diagnostic medical parasitology. ASM Press, Washington. DC

Hashemnia, M.; Rezaei, F.; Nikousefat, Z. and Ghashghaii, A. (2015): Acute caprine fasciolosis: a case with unusual migration to lung. Journal of parasitic diseases, 39(3): 514-517.

Iboyi, M.; Agada, P. and Imandeh, N. (2017): Study on the Prevalence of Fascioliasis on Cattle Slaughtered at Minna Modern Abattoir, Niger State, Nigeria. Journal of Applied Life Sciences International, 15(3): 1-6.

Khalifa, R.; El-Hady, H.A.; Omran, E.K. and Ahmed, N.S. (2013): Genetically confirmed Fasciola hepatogigantica n. sp. Journal of the Egyptian Society of Parasitology, 240(1412): $1-10$.

Kuchai, J.; Chishti, M.; Zaki, M.M.; Rasool, S.; Ahmad, J. and Tak, H. (2011): Some epidemiological aspects of fascioliasis among cattle of Ladakh. Global Veterinaria 7(4): 342-346.

Kuraa, H.M. and Malek, S.S. (2014): Parasitological and serological study on Fasciola diagnosis in cattle and buffaloes in Assiut Governorate. Assiut Veterinary Medical Journal, 60(141): 96-104.

Mehmood, K.H.; Zhang, A.J.; Sabir, R.Z.; Abbas, M. Ijaz, A.Z.; Durrani, M.H.; Saleem, M.U.; Rehman, M.K.; Iqbal, Y.; Wang, H.I.; Ahmad, T.; Abbas, R.; Hussain, M.T.; Ghori, S.; Ali, A.U. and Khan, J.Li. (2017): A review on epidemiology, global prevalence and economical losses of fasciolosis in ruminants. Microbial Pathogenesis 109, 253-262.

Nappi, A.J. (2002): Parasites of medical importance. London, New York: CRC Press Taylor \& Francis Group.

Njoku-Tony, R. (2011): Bovine fasciolosis among slaughtered cattle in selected abattoirs in Imo State, Nigeria. World Rural Observations, 3(1): 59-63.

Okaiyeto, S.; Salami, O.; Dnbirni, S.; Allam, L. and Onoja, I. (2012): Clinical, gross and histopathological changes associated with chronic fasciolosis infection in a dairy farm. Journal of Veterinary Advances, 2(8): 444448.

Okoye, I.; Egbu, F.; Ubachukwu, P. and Obiezue, N.R. (2015): Liver histopathology in bovine Fascioliasis. African Journal of Biotechnology, 14(33): 2576-2582.

Phiri, A. (2006): Common conditions leading to cattle carcass and offal condemnations at 3 abattoirs in the Western Province of Zambia and their zoonotic implications to consumers. Journal of the South African Veterinary Association, 77(1): 28-32.

Rahman, A.A.; Islam, S.S.; Talukder, M.H.; Hassan, M.K.; Dhand, N.K. and Ward, M.P. (2017): Fascioliasis risk factors and space-time clusters in domestic ruminants in Bangladesh. J Parasites \& vectors, 10(1): 228-.

Salmo, N.A.; Hassan, S.M. and Saeed, A.K. (2014): Histopathological study of chronic livers Fascioliasis of cattle in Sulaimani abattoir. AL-Qadisiyah Journal of Veterinary Medicine Sciences, 13(2): 71-80.

Youssef, A.I.; Yassien, M.A.; Ahmed, A.M. and Soliman, S.A. (2013): Prevalence, Intensity and Viability of Tissue Parasites Infected Bovine Carcasses at Ismailia-Egypt with Special Reference to their Zoonotic implications.

\section{معدل الاصابة والتغيرات النسيجية المرضية لداء المتورقات (مثقبيات الكبد) البقري مع الهجرة غير العادية

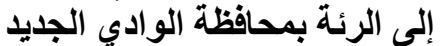

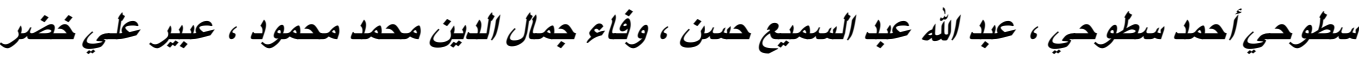

E-mail: Abeer.lalhmd49@gmail.com Assiut University web-site: www.aun.edu.eg

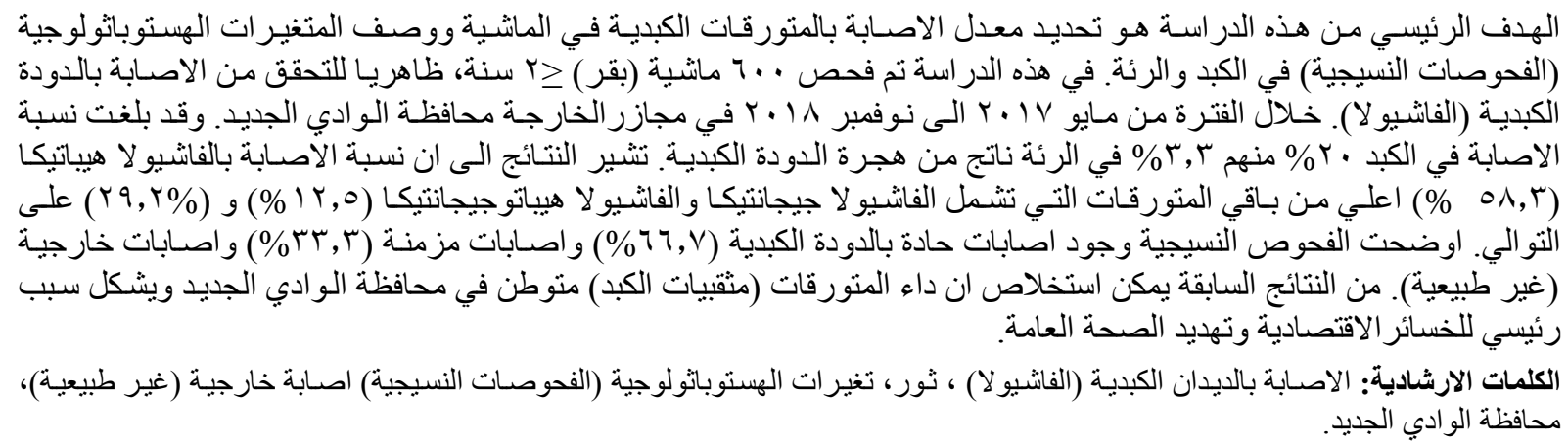

